\title{
Epidemiological Situation of Necrotizing Fasciitis and Factors in Thailand and Factors Associated with Its Morbidity and Mortality, 20I4-20I8
}

This article was published in the following Dove Press journal: Risk Management and Healthcare Policy

Panupong Tantirat ${ }^{\prime}{ }^{\prime}$

Thanit Rattanathumsakul (D)

Hirunwut Praekunatham (iD) ${ }^{2}$

Kumaree Pachanee ${ }^{3}$

Repeepong Suphanchaimat (ID)

'Division of Epidemiology, Department of Disease Control, Ministry of Public Health, Thailand; ${ }^{2}$ Division of

Occupational and Environmental

Diseases, Department of Disease

Control, Ministry of Public Health,

Nonthaburi, Thailand; ${ }^{3}$ International

Health Policy Programme, Ministry of

Public Health, Thailand
Correspondence: Panupong Tantirat

Division of Epidemiology, Department of Disease Control, Ministry of Public Health, Building I0, Floor 3, 88/2I Tiwanon Road, Talat Khwan Subdistrict, Mueang District, Nonthaburi I I000, Thailand

$\mathrm{Tel}+66878190796$

$\mathrm{Fax}+6625918581$

Email golftppanupong@gmail.com
Introduction: Necrotizing fasciitis (NF) is a rare skin and soft-tissue bacterial infection with high morbidity and mortality. Knowledge about the prevalence and incidence of NF in Thailand is quite sparse. The objective of this study was to determine the prevalence of NF in Thailand and factors that may be potentially associated with NF morbidity and mortality.

Methods: A cross-sectional study using secondary data from Thailand's national health databases between 2014 and 2018 was conducted. Descriptive statistics using median and percentage formats were used. This was complemented by multivariable logistic regression to determine the association between various factors (such as age and underlying diseases) with NF morbidity and mortality. Univariate spatial data analysis was exercised to identify the geographical hot spots in which the disease appeared.

Results: During 2014-2018, we found 90,683 NF cases. About $4.86 \%$ of the cases died. The median age for all cases was 59.39 years old. The annual incidence of NF demonstrated an upward trend (from 26.08 per 100,000 population in 2014 to 32.64 per 100,000 population in 2018). The monthly incidence was highest between May and August. A high incidence cluster (as indicated by local Moran's I) was found in the north-eastern region of Thailand. The most infected sites were on the ankles and feet (43.18\%) with an amputation rate of $7.99 \%$ in all cases. Multivariable logistic regression indicated that the significant risk factor for amputation was a presence of underlying diseases, namely diabetes (OR 7.94, 95\% CI 7.34-8.61). Risk factors for mortality included being elderly (OR 1.82, 95\% CI 1.68-1.98) and a presence of underlying hypertension (OR 1.16, 95\% CI 1.07-1.27), cirrhosis (OR 4.67, 95\% CI 4.17-5.21), and malignancy (OR 1.88, 95\% CI 1.55-2.26).

Discussion and Conclusion: As the elderly and those with chronic underlying diseases are likely to face non-preferable health outcomes from NF, healthcare providers should pay great attention to these groups of patients. Early and intensive treatment might be considered in these groups of patients. Further studies that aim to validate the volume of actual NF cases and reported NF cases are recommended.

Keywords: necrotizing fasciitis, incidence, mortality, morbidity

\section{Introduction}

Necrotizing fasciitis (NF) is a rare bacterial infection that spreads quickly in the body and can cause severe morbidity and death. ${ }^{1}$ NF can occur in healthy individuals in all age groups. ${ }^{2}$ There are four types of $\mathrm{NF}^{3}$ Type $1 \mathrm{NF}$ is caused by poly-microbial infection due to enterobacteriaceae and facultative and anaerobic streptococci. In addition, obligate aerobes and fungi have also been found to be causes. ${ }^{2,4-6}$ Type 2 NF is caused by Group A streptococcus or other beta-haemolytic streptococci. ${ }^{7}$ Type 3 $\mathrm{NF}$ is caused by Gram-negative, often marine-related organisms such as Vibrio spp, ${ }^{3}$ 
and type $4 \mathrm{NF}$ was associated with trauma. ${ }^{3}$ The main infection of this type was fungal. ${ }^{3}$

The incidence of NF worldwide ranges from $0.30-15$ cases per 100,000 population. ${ }^{8,9}$ International literature suggests that risk factors of NF include trauma, surgery, being immunecompromised hosts, malignancy, obesity, alcoholism, pregnancy, and undergoing gynecologic procedures. ${ }^{4,7,9-14}$ The mortality rate for Type $1 \mathrm{NF}$ is $21 \%$ and for Type $2 \mathrm{NF}$ is $14-34 \%{ }^{2,15-17}$ Precipitating factors of mortality are severe sepsis, serum creatinine $\geq 2.00 \mathrm{mg} / \mathrm{dl}$, age greater than 60 years old, streptococcal toxic shock syndrome, clostridial infection, delay of surgery $>24$ hours, and infection involving the head, neck, thorax, or abdomen., ${ }^{2,17-20}$

$\mathrm{NF}$ is a significant economic burden. A study in Australia showed that the total cost for treating a patient with NF ranged from $\$ 1025$ to $\$ 514,889 .{ }^{21}$ Moreover, NF may severely undermine the quality of life of patients, particularly those undergoing amputation. The high mortality rate is also a major public health concern., ${ }^{2,15-17}$

A prior domestic study by Khamnuan et al indicates that about $8.40 \%(127 / 1507)$ of NF cases ended up with limb amputation. ${ }^{22}$ Moreover, a study in Thammasat University Hospital in Thailand reported that mortality was $5.41 \%$ among NF cases, and this figure could be as high as $50 \%$ among diabetic patients. ${ }^{23}$ A lower likelihood of amputation or fatality requires early and aggressive surgical exploration and debridement with broad-spectrum empiric antibiotic therapy and hemodynamic support. ${ }^{4}$

In 2017 and 2018, a variety of media agencies in Thailand reported that increasing numbers of people are affected by NF (in lay term, "flesh-eating disease") in one of the north-eastern regions of Thailand. ${ }^{24,25}$ In this regard, the Division of Epidemiology (DOE) which sits in the Department of Disease Control (DDC) at the Thai Ministry of Public Health (MOPH) initiated a rapid assessment of the nationwide situation of NF in Thailand, which had not been reported previously. This study, also initiated by the DOE, is a deeper analysis aiming to explore the NF situation in terms of incidence and case fatality rate (CFR) and distribution by time, place and person. Furthermore, it determines factors that are potentially associated with morbidity and mortality of NF.

\section{Methods}

\section{Study Design and Data Source}

We conducted a descriptive cross-sectional study using secondary individual data service data from the National
Health Database of the MOPH (43-folders dataset). The dataset retrieves registered individual patient records from all public hospitals affiliated to the MOPH in Thailand, except in Bangkok. The analysis was separated into three parts. First, individual NF cases were used to analyse NF incidence, case fatality rate and case characteristics. Second, individual cases were grouped together to determine provincial-level data in terms of annual NF incidence and NF case fatality rate per province. The provinciallevel data were used for spatial analysis. Lastly, temporal characteristics were assessed by estimating the monthly trend of NF cases.

\section{Data Management}

The interested populations were Thai patients diagnosed with NF (International Classification of Diseases - ICD = M72.6) from 2014 to 2018. Data cleaning was processed by the following criteria. First, we identified duplicated records by personal national identification numbers; then we constructed a new dataset containing individual records which combined outpatient and inpatient data. If an individual visited a hospital twice within a window period of 180 days, those visits were grouped into a single record.

The new dataset contained the following variables: sex, age, occupation, underlying diseases (diabetes mellitus, hypertension, obesity, cirrhosis, HIV, alcoholism, and malignancy), date of first visit, address (in provincial level), infected site, treatment procedures, length of hospital stay (date of discharge subtracting date of first visit), and discharge status (recovered or death).

\section{Data Analysis \\ Descriptive Statistics}

Descriptive statistics were performed. The annual incidence proportion and case fatality rate were calculated using the estimated mid-year population from the DOE as a denominator. Characteristics by the patients were presented as percentage, mean with standard deviation (SD), and median with interquartile range (IQR) in all cases and subgroup analysis by dead status and amputation status.

\section{Univariate Spatial Analysis}

Moran's I and Local Moran's I with Moran's scatter plot were calculated on incidence proportion and case fatality rate (CFR) to assess spatial autocorrelation (I statistic approaching one indicates the clustering pattern). The results of those statistics are interpreted as a spatial 
pattern, such as the clustered pattern in which statistical value closes to positive one, a Chessboard pattern in which statistical value closes to negative one, and a random pattern which statistical value closes to zero. ${ }^{26}$

$$
I=\frac{\sum_{\mathrm{i}=1}^{\mathrm{N}} \sum_{\mathrm{j}=1}^{\mathrm{N}} \mathrm{w}_{\mathrm{ij}}\left(\mathrm{y}_{\mathrm{i}}-\overline{\mathrm{y}}\right)\left(\mathrm{y}_{\mathrm{j}}-\overline{\mathrm{y}}\right)}{\frac{1}{\mathrm{~N}} \sum_{\mathrm{i}=1}^{\mathrm{N}}\left(\mathrm{y}_{\mathrm{i}}-\overline{\mathrm{y}}\right)^{2} \sum_{\mathrm{i}=1}^{\mathrm{N}} \sum_{\mathrm{j}=1}^{\mathrm{N}} \mathrm{w}_{\mathrm{ij}}}
$$

I was Moran's I statistic, and $\mathrm{w}_{\mathrm{ij}}$ was a spatial weight matrix using Queen contiguity matrix.

$$
I_{i}=\sum_{j=1}^{N} w_{i j}^{s t d}\left(\frac{y_{i}-\bar{y}}{\sigma_{y}}\right)\left(\frac{y_{j}-\bar{y}}{\sigma_{y}}\right)
$$

\section{Temporal Analysis}

Time series analysis was performed on the total number of cases and deaths to identify temporal pattern (such as trend and seasonality) using Buys-Ballot Table. ${ }^{27}$ Linear, quadratic and exponential models were fitted to the reported data as per a standard calibration process. We assessed model fitness by comparing the number of reported cases and predicted cases in the last three months using mean absolute error (MAE), mean absolute percentage error (MAPE), root mean squad error (RMSE), and root mean squad percentage error (RMSPE) as fitness indicators. Formulae used in this step were displayed in supplemen $\underline{\text { tary file } 1 .}$

\section{Multivariable Analysis}

There were two main morbidity dependent variables: amputation and deaths. Independent variables included demographic data, underlying diseases, infected site, and operation procedures. Odds ratio (OR), adjusted OR, and 95\% confidence interval (CI) were determined by logistic regression. The selection of variables to be included in multivariable logistic regression was exercised by stepwise method (cut-off p-value $\leq 0.2$ ). We used $\mathrm{R} 3.6 .0$ and RStudio $^{\circledR}$ for all calculations.

\section{Subgroup Analysis}

As amputation and death can be competing risks, we performed subgroup analysis to assess if the association between the predictor variables and the outcome would change from the complete-set analysis. We performed two analysis steps. First, we limited the data only to those who survived, and then performed multivariable logistic regression to compare the odds of being cured with and without amputation. In the second step, we focused on those who did not undergo amputation. The outcome in this regard was cured versus dead.

\section{Data Evaluation and Data Validity}

We conducted additional analysis to assess data validity. As this study mainly used secondary data analysis, it was difficult to assess whether and to what extent the reported NF data reported the true NF cases. In this regard, we performed a rapid surveillance evaluation in a tertiary care hospital, which is one of the referral centers that receives complicated cases (including NF) in Thailand. We explored medical records of the patients who were diagnosed with NF (International Classification of Diseases Version 10 [ICD10] $=$ M72.6) and with NF-related diagnosis (such as ICD10 $=\mathrm{L} 03$, referring to cellulitis), between 2014 and 2018. We randomly extracted 50 reported NF cases and 50 reported NF-related cases from the hospital database. However, in reality, we retrieved 103 records (48 reported NF cases and 55 NF-related cases). We then reviewed the medical history of each patient to check if there was a visit that could be identified according to a NF diagnosis. We evaluated each visit as to whether it coincided with NF clinical criteria (true NF) or otherwise. The visit was identified as true NF if it met either one of the following conditions: (i) post-operative diagnosis as NF; or (ii) at least two clinical symptoms were presented (erythema, edema extending beyond visible erythema, severe pain, crepitus, and specific skin lesion such as skin bullae, necrosis, or ecchymosis). The percentage of true NF in reported NF (identified by ICD10) and among NF-related cases was determined to validate whether there was an over- or under-estimation of NF in the hospital database.

\section{Results}

A total of 155,620 outpatient (OP) and 271,668 inpatient (IP) records, which were diagnosed as NF by ICD10 coding, were retrieved. The volume of records after cleaning and discarding duplicates was 90,683. Among the NF cases, 6,786 resulted in amputation (without death) (7.48\%); 3,944 resulted in deaths (without amputation) $(4.35 \%)$ and 466 came up with amputated death $(0.51 \%)$.

The incidence proportion of NF increased from about 26.08 per 100,000 in 2014 to 32.64 per 100,000 in 2018 . Likewise, the case fatality ratio (deaths per patient) grew from about $4.30 \%$ in 2014 to $6.34 \%$ in 2018, Figure 1 .

Most of the cases were males (58.45\%), and worked as skilled agriculturists. The median age was 59.39 years and 


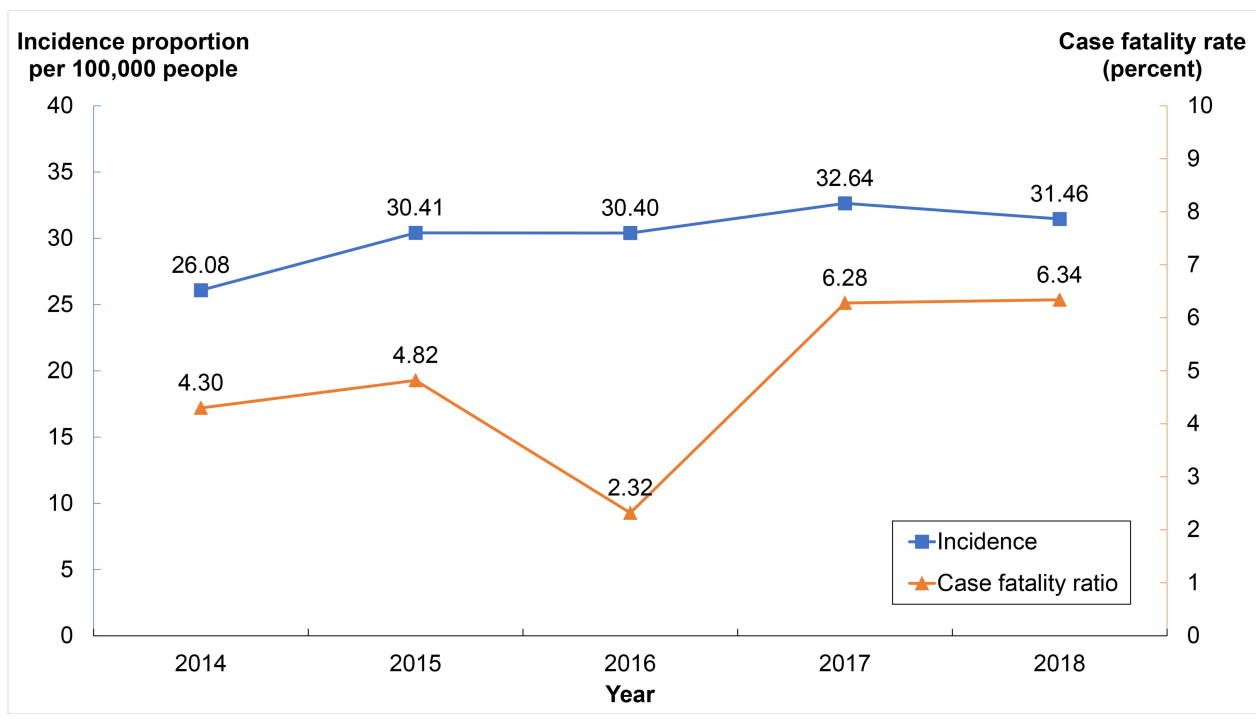

Figure I Incidence proportion and case fatality rate of NF cases, Thailand, 20I4-2018.

there were differences in the age of survival and death. The median of age among the deaths was higher than that of the whole dataset. The mean age of skilled agriculturists and general contractors were 60.23 and 53.20 years, respectively. The unemployed group had a mean age of about 66.66 years. About three quarters of the unemployed were in the elderly group. Diabetes Mellitus shared a high proportion of all underlying diseases in amputated cases while cirrhosis constituted the greatest share among deaths. Ankles and feet $(43.18 \%)$ were the most commonly amputated sites, followed by lower leg (26.74\%). In terms of hospitalization length, the median was eight days (13-16 days in amputated group and 5-8 days in nonamputated group). Intubation showed the largest share among the deaths, relative to other procedures; Table 1.

The annual incidence proportion of NF cases per 100,000 population in each province was demonstrated in Figure 2. The north-eastern region appeared to have larger incidence compared with other regions. Moran's I ranged from 0.41 to 0.54 , representing strong evidence of clustering (p-value $<0.05$ ).

By contrast, the CFR clustering was not apparent relative to incidence proportion and greatly varied by years (Moran's I $=0.002-0.29$ ), Figure 3. The detailed information of CFR and incidence proportion in each province is provided in supplementary file 2 .

Trend and seasonality of cases are identified in Figure 4. We selected quadratic trend as it showed the greatest model fitness as measured by $\mathrm{R}^{2}\left(R^{2}\right.$ for linear $=$ $0.73, \mathrm{p}$-value $=0.065 ; R^{2}$ for quadratic $=0.93, \mathrm{p}$-value $=$
0.073 and $R^{2}$ for exponential $=0.72, \mathrm{p}$-value $=0.070$ ) Seasonality pattern showed a peak between May and August. Figure 4 compares the difference between reported cases and predicted cases from different models.

The analysis on the trend of NF deaths was performed in the same fashion as total cases. The linear trend was selected for trend component as it showed the lowest $\mathrm{p}$-value with relatively similar degree of $\mathrm{R}^{2}$, reflecting the greatest model fitness $\left(R^{2}=0.43, \mathrm{p}\right.$-value $\left.=0.230\right)$, Quadratic $\left(R^{2}=0.52, \mathrm{p}\right.$-value $\left.=0.480\right)$, and Exponential $\left(R^{2}=0.30, \mathrm{p}\right.$-value $\left.=0.343\right)$ models. Seasonality was therefore revealed with a peak from May to August and was the same as the temporal analysis for total cases. Figure 5 compares the difference between reported deaths and predicted deaths from different models.

Overall, the multiplicative model showed a better fit relative to the additive model for both total-case analysis and death analysis. This was proven by many predicted indicators (MAE, MAPE, RMSE and RMSPE) as presented in Table 2.

Univariable analysis is reported in Table 3. Significant risk factors for amputation were female (OR 1.28, 95\% CI 1.21-1.35), underlying with diabetes mellitus (OR 8.65, 95\% CI 8.09-9.24), hypertension (OR 2.23, 95\% CI 2.122.34), and single sites of NF infection (OR 1.58, 95\% CI 1.25-2.00). Significant risk factors for death were being elderly, aged 60 years or above (OR 1.66, 95\% CI 1.552.77), underlying diabetes mellitus (OR 1.09, 95\% CI 1.03-1.16), hypertension (OR 1.36, 95\% CI 1.28-1.45), cirrhosis (OR 3.91, 95\% CI 3.59-4.27), alcoholism (OR 
Table I Characteristics of NF Cases

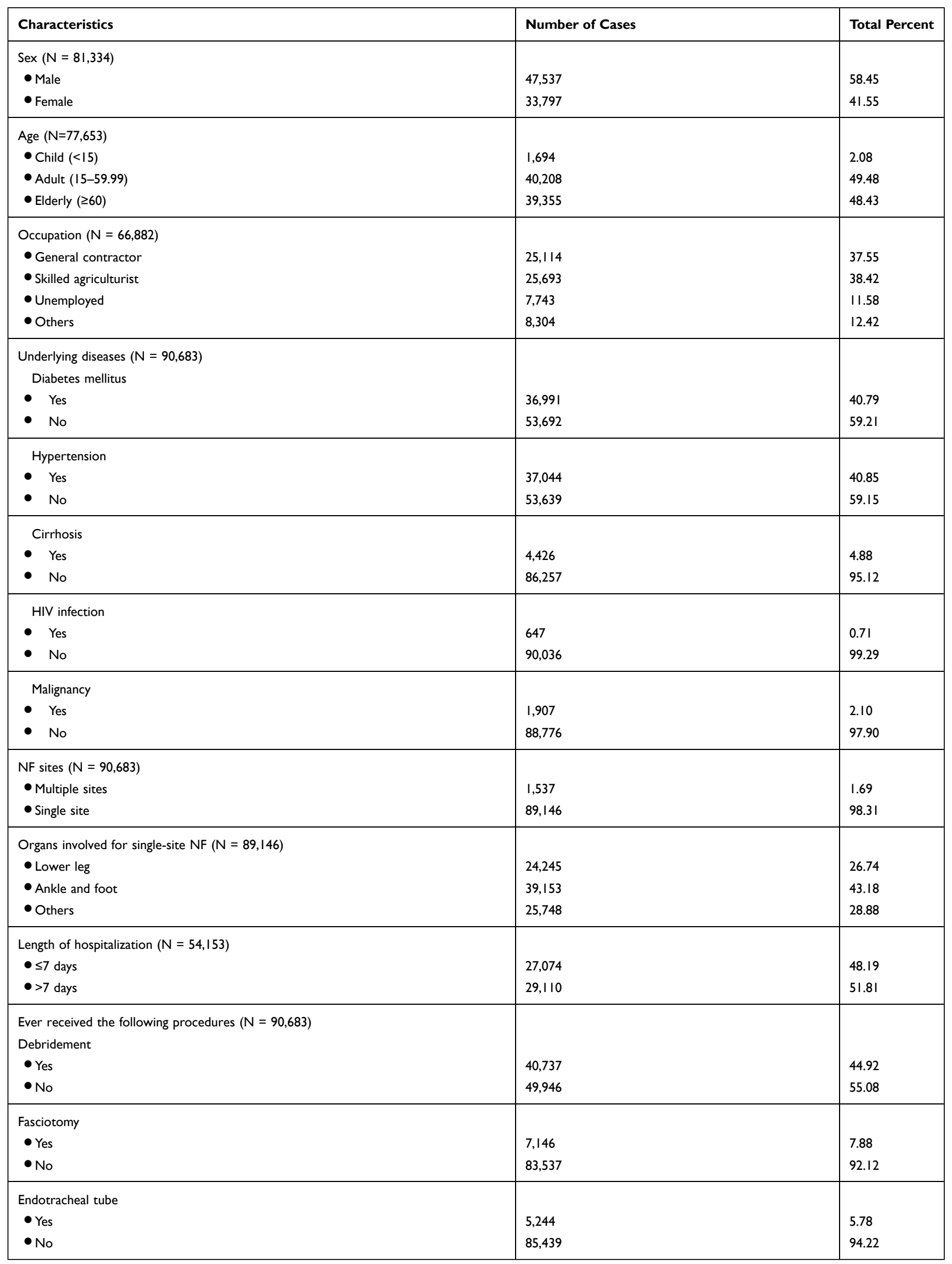




\begin{tabular}{|c|c|c|c|c|c|}
\hline Year & 2014 & 2015 & 2016 & 2017 & 2018 \\
\hline Moran's I & $0.41^{*}$ & $0.51^{*}$ & $0.46^{*}$ & $0.51^{*}$ & $0.54^{\star}$ \\
\hline \multicolumn{6}{|l|}{ Incidence by } \\
\hline $\begin{array}{l}\text { Legend } \\
\text { (/100,000 people) }\end{array}$ & $\begin{array}{r}68.68-85.17 \\
43.40-68.68 \\
22.06-43.40 \\
10.46-22.06 \\
1.87-10.46 \\
\end{array}$ & 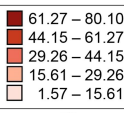 & 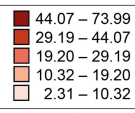 & $\begin{array}{r}77.55-105.19 \\
46.10-77.55 \\
28.62-46.10 \\
14.54-28.62 \\
2.16-14.54 \\
\end{array}$ & 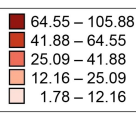 \\
\hline \multicolumn{6}{|l|}{$\begin{array}{l}\text { Local Moran's I } \\
\text { mapping }\end{array}$} \\
\hline $\begin{array}{l}\text { 口 High - High } \\
\text { Q Low - Low } \\
\square \text { High - Low } \\
\square \text { Low - High } \\
\square \text { Not Sig. }\end{array}$ & & & & & \\
\hline
\end{tabular}

Figure 2 Incidence proportion of NF by areas with spatial data, Thailand, 20I4-20I8. Note: *P-value $<0.01$.

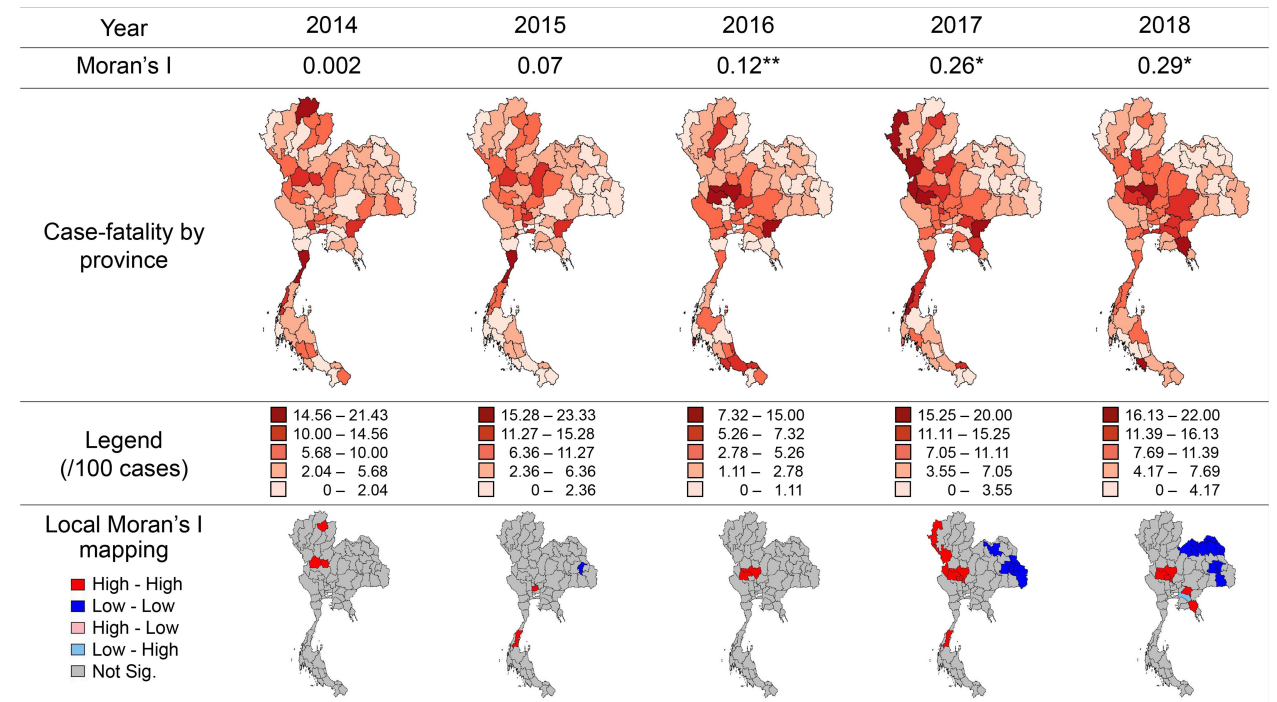

Figure 3 Case fatality rate of NF by areas with spatial, Thailand, 2014-2018.

Notes: *P-value $<0.01$, **P-value $<0.05$.

$1.56,95 \%$ CI 1.34-1.81), and malignancy (OR 2.22, 95\% CI 1.91-2.58).

In multivariable analysis, sex, age, occupation, underlying diseases, and NF infected site were included in multivariable logistic regression (Table 4). A significant factor for amputation was underlying diabetes mellitus (adjusted OR 7.94, 95\% CI 7.34-8.61) and significant factors for mortality were being elderly (adjusted OR 1.82, 95\% CI 1.68-1.98), underlying hypertension (adjusted OR 1.16, 95\% CI 1.071.27), cirrhosis (adjusted OR 4.67, 95\% CI 4.17-5.21), and malignancy (adjusted OR 1.88, 95\% CI 1.55-2.26).
Table 5 shows results from subgroup analysis. Findings from subgroup analysis were quite similar to the findings from full-sample analysis. Diabetes appeared to be the strongest risk factor for amputation (even after excluding dead cases) with adjusted $\mathrm{OR}=8.53$; and $95 \% \mathrm{CI}=7.86-9.27$. For non-amputated cases, cirrhosis still presented as the strongest risk factor for death (adjusted OR 4.70, 95\% CI 4.12-5.13).

By comparing the existing medical records of NF and NF-related patients against the reported data in a selected hospital, we discovered that, out of 48 reported NF cases (as defined by IC10 coding), 43 met the clinical definition 


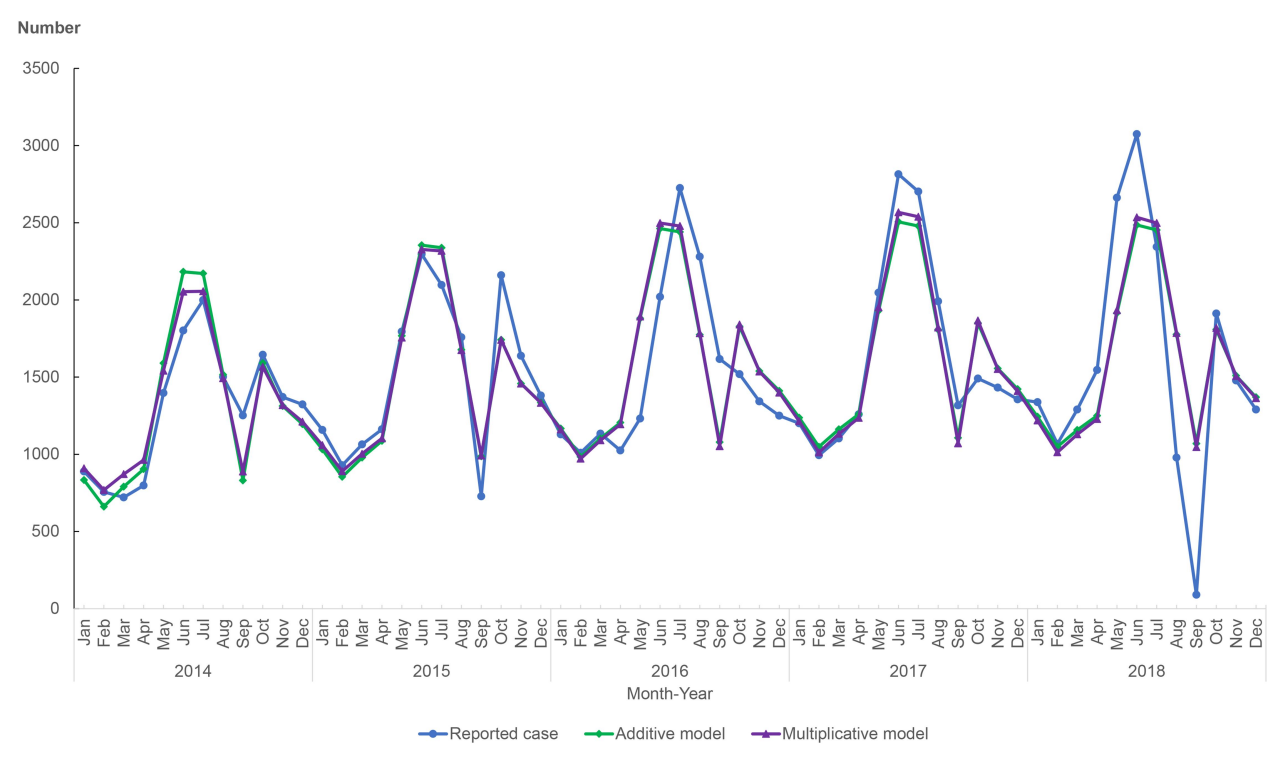

Figure 4 Reported NF cases and predicted NF cases from additive and multiplicative models, Thailand, 20I4-20I8.

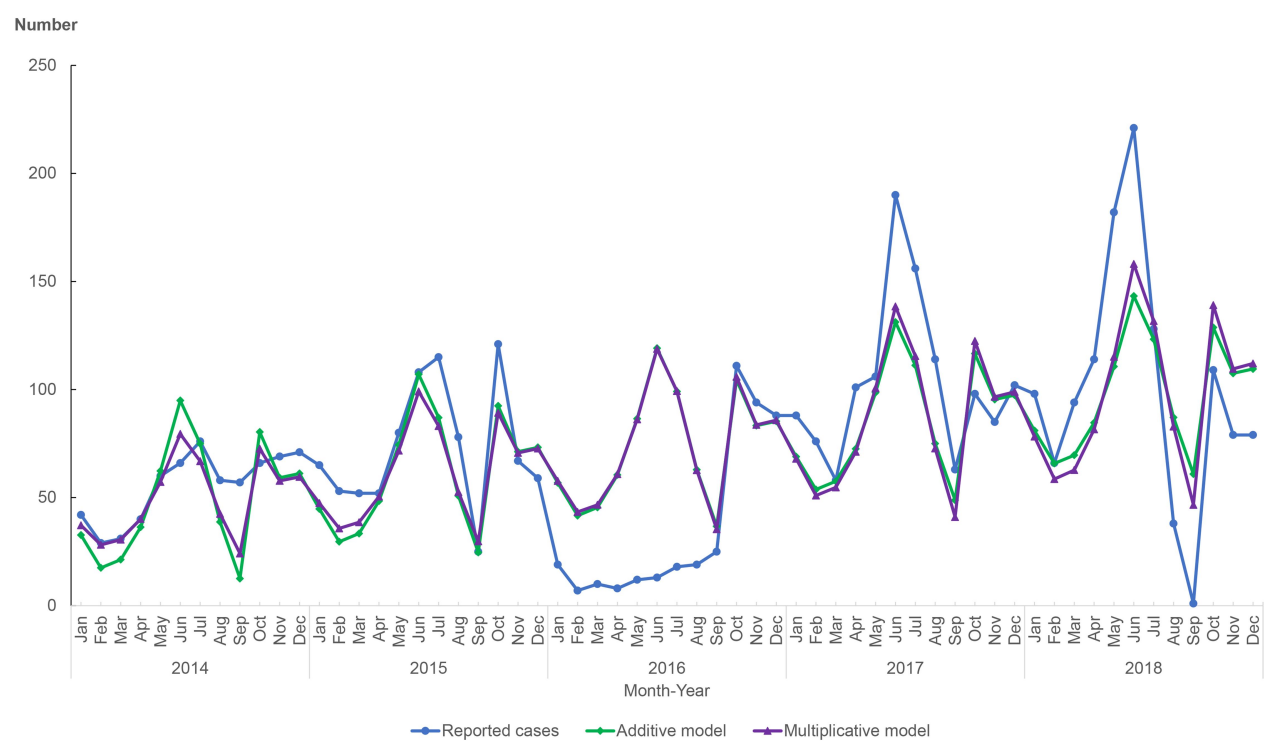

Figure 5 Reported deaths and predicted deaths from additive and multiplicative models in NF patients, Thailand, 20I4-2018.

of NF. This meant the reported NF cases overestimated the true cases by about $10.42 \%$ (or the positive predictive value of reporting equated $89.58 \%$ ). All 43 cases that met clinical definition of NF were reported as NF by ICD10 coding, as presented in Table 6.

\section{Discussion}

Overall, we found that the yearly incidence of NF in Thailand presented in this study was higher than reports in other countries such as Norway, Canada, and the US. ${ }^{11,16,28,29}$ This suggests that NF is likely one of the most critical public health threats in Thailand. A prior study by Khamnuan et al found NF incidence to be about 15.5 cases per 100,000 population, drawn from samples in three provinces in the northern region of Thailand. Such a figure was quite close to our study findings, which showed that the incidence in corresponding provinces varied from about 13.97-18.47 cases per 100,000 population. ${ }^{22}$

The hot spot was identified in the Northeast of Thailand by local Moran's I mapping. Spatial patterns of NF between 2014 and 2018 seemed to be consistent over time. This provides indicative evidence that being involved in agriculture may play a key role in developing NF since almost half of the agricultural areas in Thailand are in the northeastern 
Table 2 Model Error Assessing the Number of NF Cases and NF Deaths

\begin{tabular}{|l|l|l|l|l|l|l|l|}
\hline Interesting Variable & Fitting Type & Model Type & $\mathbf{R}^{2}$ & MAE & MAPE & RMSE & RMSPE \\
\hline NF cases & Self-fitting & Additive & 0.75 & 208.35 & 30.84 & 297.10 & 141.75 \\
& & Multiplicative & 0.75 & 198.99 & 29.95 & 290.13 & 138.44 \\
\cline { 2 - 8 } & Next 3-month fitting & Additive & 0.36 & 209.58 & 29.88 & 278.62 & 43.91 \\
& & Multiplicative & 0.32 & 206.10 & 29.26 & 274.70 & 43.17 \\
\hline NF deaths & Self-fitting & Additive & 0.46 & 25.29 & 34.28 & 184.02 & 796.54 \\
& & Multiplicative & 0.48 & 24.52 & 32.99 & 159.25 & 619.63 \\
\cline { 2 - 8 } & \multirow{2}{*}{ Next 3-month fitting } & Additive & 1.34 & 31.26 & 150.70 & 39.71 & 237.85 \\
& & Multiplicative & 0.77 & 22.15 & 119.65 & 32.01 & 197.93 \\
\hline
\end{tabular}

Table 3 Univariate Analysis of Treatment Outcomes and Personal Attributes

\begin{tabular}{|c|c|c|c|}
\hline \multicolumn{2}{|l|}{ Factors } & \multirow{2}{*}{$\begin{array}{l}\text { OR for Amputation } \\
(95 \% \mathrm{Cl})\end{array}$} & \multirow{2}{*}{$\begin{array}{l}\text { OR for Death } \\
(95 \% \mathrm{CI})\end{array}$} \\
\hline Sex & Female & & \\
\hline Age & $\begin{array}{l}\text { Adult }(15-59.99) \\
\text { Child }(<15) \\
\text { Elderly }(\geq 60)\end{array}$ & $\begin{array}{l}\text { Ref. } \\
0.11(0.07-0.18) \\
1.05(1.00-1.057)\end{array}$ & $\begin{array}{l}\text { Ref. } \\
0.21(0.12-0.35) \\
1.65(1.54-1.76)\end{array}$ \\
\hline Occupation & $\begin{array}{l}\text { Unemployed } \\
\text { General contractor } \\
\text { Skilled agriculturist } \\
\text { Others }\end{array}$ & $\begin{array}{l}\text { Ref. } \\
0.81(0.74-0.89) \\
0.87(0.78-0.97) \\
0.87(0.80-0.96)\end{array}$ & $\begin{array}{l}\text { Ref. } \\
0.84(0.76-0.95) \\
0.49(0.44-0.54) \\
0.71(0.62-0.8 I)\end{array}$ \\
\hline Diabetes Mellitus (v no) & Yes & $7.98(7.50-8.49)$ & $0.97(0.88-1.00)$ \\
\hline Hypertension (v no) & Yes & $2.21(2.10-2.31)$ & $1.27(1.20-1.36)$ \\
\hline Cirrhosis (v no) & Yes & $0.53(0.46-0.62)$ & $4.07(3.73-4.44)$ \\
\hline HIV (v no) & Yes & $0.54(0.36-0.77)$ & $1.29(0.92-1.76)$ \\
\hline Alcoholism (v no) & Yes & $0.45(0.36-0.55)$ & $1.63(1.40-1.89)$ \\
\hline Malignancy (v no) & Yes & $0.69(0.56-0.83)$ & $2.27(1.95-2.63)$ \\
\hline Admission days ( $\leq 7$ day) & >7 days & $2.6(2.50-2.84)$ & $0.80(0.75-0.85)$ \\
\hline Debridement (v no) & Yes & $2.61(2.48-2.74)$ & $1.06(1.01-1.14)$ \\
\hline Fasciotomy (v no) & Yes & $0.97(0.89-1.07)$ & $1.32(1.19-1.46)$ \\
\hline Endotracheal tube ( $v$ no) & Yes & $1.96(1.81-2.13)$ & $16.00(14.93-17.14)$ \\
\hline NF site ( $v$ multiple sites) & Single site & $1.49(1.21-1.87)$ & $0.66(0.54-0.8 \mathrm{I})$ \\
\hline
\end{tabular}

region. ${ }^{30}$ Furthermore, the number of NF cases each year reached its peak between May and August, which is a cropplanting period. A study by Gerberich et al and a study by Cogbill and Busch suggested that agricultural work is associated with an increased incidence of trauma. ${ }^{31,32}$ Trauma, such as skin trauma, increases the chance of skin infection. ${ }^{9}$ Then, simple skin infections can rapidly progress to necrotizing fasciitis. ${ }^{9}$ We also attempted to explore if the degree of land use was correlated with the incidence of NF. Unfortunately, the data from the Office of Agriculture and Economics, Ministry of Agriculture and Co-operatives, were not complete and clean enough to perform correlation analysis. However, we still found some suggestive evidence indicating that in each year, the area of land used for rice cropping soared during June and July, then sharply declined in October to December. This rise-and-fall pattern was quite similar to the seasonal fluctuation of the volume of NF cases. $^{33}$

The CFR in this study was smaller, compared with that reported in Canada, Singapore, and Sweden. However, the interpretation of this discovery should be made with caution as most studies on CFR were conducted in the 1990 s to 2000 s, a period when treatment and medicine were not advanced relative to the current 
Table 4 Multivariable Analysis of Treatment Outcomes and Personal Attributes

\begin{tabular}{|c|c|c|c|}
\hline \multicolumn{2}{|l|}{ Factors } & \multirow{2}{*}{$\begin{array}{l}\text { OR-Amputation } \\
\text { (95\% CI) } \\
0.96(0.90-1.02)\end{array}$} & \multirow{2}{*}{$\begin{array}{l}\text { OR-Death } \\
(95 \% \mathrm{CI})\end{array}$} \\
\hline Sex & Female & & \\
\hline Age & Adult (15-59.99) & Ref. & Ref. \\
\hline & Child $(<15)$ & $0.27(0.07-0.72)$ & $0.40(0.16-0.82)$ \\
\hline & Elderly $(\geq 60)$ & $0.93(0.87-0.99)$ & $1.82(1.68-1.98)$ \\
\hline \multirow[t]{4}{*}{ Occupation } & Unemployed & Ref. & Ref. \\
\hline & General contractor & $0.83(0.76-0.92)$ & $1.04(0.93-1.16)$ \\
\hline & Skilled agriculturist & $0.75(0.68-0.82)$ & $0.55(0.49-0.61)$ \\
\hline & Other & $0.74(0.66-0.83)$ & $0.80(0.70-0.92)$ \\
\hline Diabetes Mellitus (v no) & Yes & $7.94(7.34-8.6 I)$ & $0.86(0.79-0.93)$ \\
\hline Hypertension (v no) & Yes & $1.00(0.94-1.07)$ & $1.16(1.07-1.27)$ \\
\hline Cirrhosis (v no) & Yes & $0.6 \mathrm{I}(0.5 \mathrm{I}-0.73)$ & $4.67(4.17-5.21)$ \\
\hline HIV (v no) & Yes & $0.67(0.42-1.02)$ & $1.23(0.81-1.80)$ \\
\hline Alcoholism ( $v$ no) & Yes & $0.68(0.52-0.86)$ & $1.02(0.84-1.22)$ \\
\hline Malignancy (v no) & Yes & $0.68(0.53-0.86)$ & I.88 (I.55-2.26) \\
\hline NF site ( $v$ multiple sites) & Single site & $1.30(1.00-1.73)$ & $0.76(0.59-0.99)$ \\
\hline
\end{tabular}

Table 5 Multivariable Analysis in Subgroup Analysis

\begin{tabular}{|c|c|c|c|}
\hline \multicolumn{2}{|l|}{ Factors } & \multirow{2}{*}{$\begin{array}{l}\text { OR-Amputation } \\
\text { (95\% CI): Subgroup Analysis I } \\
0.95(0.90-1.01)\end{array}$} & \multirow{2}{*}{$\begin{array}{l}\text { OR-Death } \\
(95 \% \mathrm{CI}): \text { Subgroup Analysis } 2 \\
1.00(0.93-1.08)\end{array}$} \\
\hline Sex & Female & & \\
\hline Age & $\begin{array}{l}\text { Adult }(15-59.99) \\
\text { Child }(<15) \\
\text { Elderly }(\geq 60)\end{array}$ & $\begin{array}{l}\text { Ref. } \\
0.20(0.03-0.6 I) \\
0.91(0.86-0.97)\end{array}$ & $\begin{array}{l}\text { Ref. } \\
0.38(0.15-0.78) \\
1.80(1.66-1.95)\end{array}$ \\
\hline Occupation & $\begin{array}{l}\text { Unemployed } \\
\text { General contractor } \\
\text { Skilled agriculturist } \\
\text { Other }\end{array}$ & $\begin{array}{l}\text { Ref. } \\
0.80(0.72-0.89) \\
0.75(0.68-0.83) \\
0.68(0.61-0.78)\end{array}$ & $\begin{array}{l}\text { Ref. } \\
0.99(0.89-1.12) \\
0.53(0.47-0.59) \\
0.76(0.66-0.87)\end{array}$ \\
\hline Diabetes Mellitus ( $v$ no) & Yes & $8.53(7.86-9.27)$ & $0.99(0.91-1.07)$ \\
\hline Hypertension (v no) & Yes & $0.99(0.93-1.03)$ & $1.18(1.08-1.28)$ \\
\hline Cirrhosis (v no) & Yes & $0.60(0.49-0.72)$ & $4.60(4.12-5.13)$ \\
\hline HIV (v no) & Yes & $0.67(0.4 I-1.03)$ & $1.28(0.86-1.85)$ \\
\hline Alcoholism (v no) & Yes & $0.75(0.58-0.95)$ & $1.00(0.83-1.20)$ \\
\hline Malignancy (v no) & Yes & $0.72(0.56-0.92)$ & $1.82(1.51-2.19)$ \\
\hline NF site ( $v$ multiple sites) & Single site & $1.34(1.02-1.80)$ & $0.77(0.60-1.00)$ \\
\hline
\end{tabular}

Notes: Subgroup analysis I = excluding deaths; subgroup analysis 2 = excluding amputated cases.

setting. $2,11,15-17,28,29$ There was a slight fluctuation in CFR in Thailand in 2016, when CFR plummeted in comparison with the overall increasing trend. The reason behind this phenomenon remains questionable and requires further investigation.

The temporal analysis confirmed a temporal pattern of NF, either by additive model or multiplicative model. The multiplicative model seemed to better fit the data.
The amputation rate among NF cases in this study was about $8 \%$, which was similar to the study by Khamnuan et al. ${ }^{22}$ The rate of amputation was greater among adults, relative to children. This can be partly explained by the fact that the immune system of a patient gradually decreases by age and adults are likely to have many more comorbidities than children. Some of these morbidities can weaken the human immune system. ${ }^{34,35}$ 
Table 6 Comparing Reported NF Cases Against True NF Cases That Met Clinical Criteria

\begin{tabular}{|l|l|l|l|}
\hline & Meeting Clinical Criteria of NF & Not Meeting Clinical Criteria of NF & Total \\
\hline ICD- I0: NF & 43 & 5 & 48 \\
ICD-I0: NF-related & 0 & 55 & 55 \\
Total & 43 & 60 & 103 \\
\hline
\end{tabular}

The univariate analysis displayed a contradicting result against descriptive statistics; that is, compared with being unemployed, being involved in agriculture seemed to have lower odds of developing NF (OR $<1)$. This might be due to misclassification bias. In Thailand, many people who are identified as unemployed may be engaged in homebased agriculture in practice. Further studies on this point are warranted.

It should be noted that we attempted to validate if the magnitude of reported NF genuinely reflected true cases. It was difficult to validate this within the given time-frame as it requires primary data collection, and an in-depth review of all related medical charts. We contacted one of the hospitals that accommodated a number of NF cases and fortunately the hospital director allowed the research team to examine the relevant medical records. We found that reported NF cases were likely to overestimate true cases by $10.42 \%$. This serves as a reminder if readers wish to generalize findings on NF magnitude in order to represent the true NF situation in Thailand. However, the issue might not severely undermine analysis to assess the association between risk factors and clinical outcomes (death, cured, and amputation). This is because death and amputation are serious health outcomes that are linked to the reimbursement of medical charges from the National Health Security Office, the main governing body of the national insurance scheme of the Thai citizens. Unlike the coding for diagnosis, clinical outcomes are rarely misclassified.

We also attempted to assess if problems about competing risks occurred in this study. We found that the findings from subgroup analysis were quite similar to the findings from full sample analysis. However, the problem of competing risks is not totally excluded. For example, the findings still showed that HIV and cirrhosis appeared to be a protective factor for amputation, while diabetes served as the strongest determinant for amputation in NF patients. This might be explained by the interaction between diabetes and other underlying chronic diseases. Patients with multiple chronic diseases (such as diabetes and HIV at the same time) were small in number, relative to those with a single disease. To prove this assumption, further studies that incorporate the interaction terms between diseases in the model are recommended. To address the competing risks, the hospital database should be re-orientated to allow the addition of time-to-event variables (such as duration from the first diagnosis to amputation) for each individual patient. This will allow for a more delicate analysis of the risks of each health outcome, not only in NF cases, but in all inpatients in public facilities.

There remain some limitations in this study. First, some variables contain a large number of missing data, such as occupation (26.24\%). During the analyses by logistic regression, missing values were dropped by default. This meant the statistical power was more or less undermined. Second, some key variables, particularly the treatment information and clinical data, such as wound characteristics, causing organisms, and laboratory findings including blood culture, were absent in the National Health Database. To investigate these data in greater detail, it is necessary to explore individual records in each healthcare facility, which requires huge amounts of human resources and time. The last limitation is the lack of household data, since the nature of the National Health Database covers only those patients who show up at health facilities affiliated to the MOPH. In other words, the data are neither able to capture patients in the private sector nor those who remained in households without showing up at the facilities. Therefore, generalizing the findings to the whole population necessitates careful interpretation.

In terms of public health implications, the Thai DDC should develop a sentinel surveillance system for NF, especially in the northeastern region of Thailand. Moreover, health workers in the high incidence area should be trained to provide early diagnosis and intensive treatment for NF patients, particularly the high risk groups of amputation and death (elderly populations, patients with chronic underlying diseases that may undermine the immune system such as diabetes, cirrhosis, and malignancy). Risk communication and adequate protective equipment should be provided to people in the agricultural sector, particularly during the cropping season. 


\section{Conclusion}

The incidence of NF in Thailand is on the rise. The northeastern region is an area where NF cases are concentrated. In each year we studied, the case volume soared during the cropping season (May to August). In-depth analysis revealed that the elderly and patients with undermined immune systems, particularly diabetes, cirrhosis and malignancy, were at greater risk of amputation and death. A morbidity sentinel surveillance system as well as adequate risk communication is likely to play a significant role in facilitating the enrollment of patients to receive proper treatment and avoid new cases, especially among the high-risk groups. Further studies that examine patients' data at a household level are of substantial value for public health implications.

\section{Ethical Consideration}

As this study is part of the routine monitoring system of the Thai DDC and only secondary data were used, no ethical clearance is necessary. However, in this study, the researchers strictly followed ethical standards in research, that is, all individual information was strictly kept confidential and not reported in the paper.

\section{Acknowledgments}

Open Access funding provided by the Qatar National Library. The authors thank the Health Data Center (HDC) and Information and Communication Technology Center of the Office of the Permanent Secretary in providing the data. Funding for publication was supported by IHPP.

\section{Author Contributions}

All authors made substantial contributions to conception and design, acquisition of data, or analysis and interpretation of data; took part in drafting the article or revising it critically for important intellectual content; agreed to submit to the current journal; gave final approval of the version to be published; and agree to be accountable for all aspects of the work.

\section{Funding}

This project was funded by the Field Epidemiology Training Program (FETP), Division of Epidemiology, Department of Disease control, Ministry of Public Health, Thailand. Funding for publication was supported by International Health Policy Program (IHPP), Ministry of Public Health, Thailand.

\section{Disclosure}

The authors declare no conflicts of interest for this work.

\section{References}

1. US CDC. Necrotizing fasciitis: all you need to know; 2018. Available from: https://www.cdc.gov/groupastrep/diseases-public/necrotizingfasciitis.html. Accessed May 24, 2019.

2. Wong $\mathrm{CH}$, Chang HC, Pasupathy S, Khin LW, Tan JLLC. Necrotizing fasciitis: clinical presentation, microbiology, and determinants of mortality. J Bone Joint Surg Am. 2003;85(A(8)):1454. doi:10.2106/00004623-200308000-00005

3. Morgan MS. Diagnosis and management of necrotising fasciitis: a multiparametric approach. $J$ Hosp Infect. 2010;75(4):249-257. doi:10.1016/j.jhin.2010.01.028

4. Goldstein EJC, Anaya DA, Dellinger EP. Necrotizing soft-tissue infection: diagnosis and management. Clin Infect Dis. 2007;44 (5):705-710. doi:10.1086/511638

5. Brook IFE. Clinical and microbiological features of necrotizing fasciitis. J Clin Microbiol. 1995;33(9):2382. doi:10.1128/JCM.33.9.23 82-2387.1995

6. Horn CB, Wesp BM, Fiore NB, et al. Fungal infections increase the mortality rate three-fold in necrotizing soft-tissue infections. Surg Infect (Larchmt). 2017;18(7):793-798. doi:10.1089/sur.2017.164

7. Miller LG, Perdreau-Remington F, Rieg G, et al. Necrotizing fasciitis caused by community-associated methicillin-resistant staphylococcus aureus in Los Angeles. $N$ Engl J Med. 2005;352(14):1445-1453. doi:10.1056/NEJMoa042683

8. Das DK, Baker MG, Venugopal K. Increasing incidence of necrotizing fasciitis in New Zealand: a nationwide study over the period 1990 to 2006. J Infect. 2011;63(6):429-433. doi:10.1016/j.jinf.2011.07.019

9. Stevens DL, Bryant AE. Necrotizing soft-tissue infections. Longo DL, ed. $N$ Engl J Med. 2017;377(23):2253-2265. doi:10.1056/ NEJMra1600673

10. Hasham S, Matteucci P, Stanley PRW, Hart NB. Necrotising fasciitis. BMJ. 2005;330(7495):830-833. doi:10.1136/bmj.330.7495.830

11. Devel H, Society P, Pediatric C, Program S. Epidemiology and Outcome of Necrotizing Fasciitis in Children: An Active Surveillance Study of the Canadian Paediatric Surveillance Program. 2007.

12. Aebi C, Ahmed A, Ramilo O. Bacterial complications of primary varicella in children. Clin Infect Dis. 1996;23(4):698-705. doi:10.1093/clinids/23.4.698

13. Beaudoin AL, Torso L, Richards K, et al. Invasive group A streptococcus infections associated with liposuction surgery at outpatient facilities not subject to state or federal regulation. JAMA Intern Med. 2014;174(7):1136. doi:10.1001/jamainternmed.2014.1875

14. Gupta Y, Chhetry M, Pathak KR, et al. Risk factors for necrotizing fasciitis and its outcome at a tertiary care centre. J Ayub Med Coll Abbottabad. 2016;28(4):680.

15. Stevens DL, Tanner MH, Winship J, et al. Severe group A streptococcal infections associated with a toxic shock-like syndrome and scarlet fever toxin A. N Engl J Med. 1989;321(1):1-7. doi:10.1056/ NEJM198907063210101

16. Fasciitis N, Features C, Kaul R, et al. Population-based surveillance for group a streptococcal necrotizing fasciitis: clinical features, prognostic indicators, and microbiologic analysis of seventy-seven cases. Am J Med. 1997;6:18-24.

17. Darenberg J, Luca-Harari B, Jasir A, et al. Molecular and clinical characteristics of invasive group A streptococcal infection in Sweden. Clin Infect Dis. 2007;45(4):450-458. doi:10.1086/519936 
18. Anaya DA. Predictors of mortality and limb loss in necrotizing soft tissue infections. Arch Surg. 2005;140(2):151. doi:10.1001/archsurg. 140.2 .151

19. Huang K-F, Hung M-H, Lin Y-S, et al. Independent predictors of mortality for necrotizing fasciitis: a retrospective analysis in a single institution. J Trauma Inj Infect Crit Care. 2011;71(2):467-473. doi:10.1097/TA.0b013e318220d7fa

20. Urbina T, Madsen MB, de Prost N. Understanding necrotizing soft tissue infections in the intensive care unit. Intensive Care Med. 2020. doi:10.1007/s00134-020-06071-w

21. Widjaja AB, Tran A, Cleland H, Leung M, Millar I. The hospital costs of treating necrotizing fasciitis. ANZ J Surg. 2005;75(12):10591064. doi:10.1111/j.1445-2197.2005.03622.x

22. Khamnuan P, Chongruksut W, Jearwattanakanok K, Patumanond J, Tantraworasin A. Necrotizing fasciitis: epidemiology and clinical predictors for amputation. Int J Gen Med. 2015;8:195-202. doi:10.2147/IJGM.S82999

23. Awsakulsutthi S. A retrospective review of necrotizing fasciitis in a regional hospital in Thammasat university. J Med Assoc Thai.20 12;93:246-253.

24. Numerous patients, "flesh-eating disease," chemicals were a risk factor? Thai PBS. Available from: https://news.thaipbs.or.th/content/ 274103. Accessed September 24, 2019.

25. AGENCY I. Found Nongbualamphu farmers use concentrated parvats - expected to import more than 8 hundred thousand liters/year. The governor ordered to hasten to find the cause. Available from: https://www.isranews.org/thaireform/thaireform-news/62051-para62051.html. Accessed May 24, 2019.

26. Kirkegaard EOW. Some methods for measuring and correcting for spatial autocorrelation. Available from: https://thewinnower.com/ papers/2847-some-methods-for-measuring-and-correcting-for-spatialautocorrelation. Accessed May 23, 2019.

27. Iwueze IS, Nwogu EC, Johnson O, Ajaraogu JC. Uses of the buysballot table in time series analysis. Appl Math. 2011;02 (January):633-645. doi:10.4236/am.2011.25084

28. Naseer U, Steinbakk M, Blystad H, Caugant DA. Epidemiology of invasive group A streptococcal infections in Norway 2010-2014: a retrospective cohort study. Eur J Clin Microbiol Infect Dis. 2016;35 (10):1639-1648. doi:10.1007/s10096-016-2704-y

29. Mulla ZD, Gibbs SG, Aronoff DM. Correlates of length of stay, cost of care, and mortality among patients hospitalized for necrotizing fasciitis. Epidemiol Infect. 2007;135(5):868-876. doi:10.1017/S0950 268806007448

30. Office of Agricultural Economics. Area of agricultural use in the province in 2017; 2017. Available from: http:/www.oae.go.th/ assets/portals/1/news/31064/1_Land Utilization2560.pdf. Accessed May 23, 2019.

31. Gerberich SG, Gibson RW, French LR, et al. Injuries among children and youth in farm households: regional rural injury study-I. Inj Prev. 2001;7(2):117-122. doi:10.1136/ip.7.2.117

32. Cogbill TH, Busch HM. The spectrum of agricultural trauma. $J$ Emerg Med. 1985;3(June):205-210. doi:10.1016/0736-4679(85)90 073-3

33. Office of Agricultural Economics. Agricultural economic information. Available from: http://www.oae.go.th/view/1/Information/ENUS. Accessed July 19, 2020.

34. Casqueiro J, Casqueiro J, Alves C. Infections in patients with diabetes mellitus: a review of pathogenesis. Indian J Endocrinol Metab. 2012;16(7):27-36. doi:10.4103/2230-8210.94253

35. Nicholson LB. The immune system. N Engl J Med. 2016;(July):275301. doi:10.1042/EBC20160017
Risk Management and Healthcare Policy

\section{Publish your work in this journal}

Risk Management and Healthcare Policy is an international, peerreviewed, open access journal focusing on all aspects of public health, policy, and preventative measures to promote good health and improve morbidity and mortality in the population. The journal welcomes submitted papers covering original research, basic science, clinical \& epidemiological studies, reviews and evaluations,

\section{Dovepress}

guidelines, expert opinion and commentary, case reports and extended reports. The manuscript management system is completely online and includes a very quick and fair peer-review system, which is all easy to use. Visit http://www.dovepress.com/testimonials.php to read real quotes from published authors. 